\title{
Distribution of phylogenetic groups, adhesin genes, biofilm formation, and antimicrobial resistance of uropathogenic Escherichia coli isolated from hospitalized patients in Thailand
}

\author{
Nipaporn Tewawong ${ }^{\text {Corresp., }}{ }^{1}$, Siriporn Kowaboot ${ }^{1}$, Yaowaluk Pimainog ${ }^{1}$, Naiyana Watanagul ${ }^{2}$, Thanunrat Thongmee \\ 3 , Yong Poovorawan ${ }^{3}$ \\ ${ }^{1}$ Faculty of Medical Technology, Rangsit University, Muang, Pathumthani, Thailand \\ 2 Department of Microbiology, Nopparat Rajathanee Hospital, Khannayao, Bangkok, Thailand \\ ${ }^{3}$ Center of Excellence in Clinical Virology, Department of Pediatrics, Faculty of Medicine, Chulalongkorn University, Pathumwan, Bangkok, Thailand \\ Corresponding Author: Nipaporn Tewawong \\ Email address: nipaporn.t@rsu.ac.th
}

Background: Urinary tract infections (UTIs) are the most common bacterial infections and are often caused by uropathogenic Escherichia coli (UPEC). We investigated the distribution of phylogenetic groups, adhesin genes, antimicrobial resistance, and biofilm formation in $E$. coli isolated from patients with UTIs.

Methods: In the present study, 208 UPEC isolated from Thai patients were classified into phylogenetic groups and adhesin genes were detected using multiplex PCR. Antimicrobial susceptibility testing was performed using agar disk diffusion. The Congo red agar method was used to determine the ability of the UPEC to form biofilm.

Results: The most prevalent UPEC strains in this study belonged to phylogenetic group B2 (58.7\%), followed by group $\mathrm{C}(12.5 \%)$, group $\mathrm{E}(12.0 \%)$, and the other groups (16.8\%). Among adhesin genes, the prevalence of fimH (91.8\%) was highest, followed by pap (79.3\%), sfa (12.0\%), and afa (7.7\%). The rates of resistance to fluoroquinolones, trimethoprim-sulfamethoxazole, and amoxicillin-clavulanate were $\sim 65 \%, 54.3 \%$, and $36.5 \%$, respectively. The presence of adhesin genes and antibiotic resistance were more frequent in groups B2 and C compared to the other groups. Of the 129 multidrug-resistant UPEC strains, 54\% were biofilm producers. Our findings further indicated that biofilm production was significantly correlated with the pap adhesin gene $(p \leq 0.05)$.

Conclusion: These findings provide molecular epidemiologic data, antibiotic resistance profiles, and the potential for biofilm formation among UPEC strains that can inform further development of the appropriate prevention and control strategies for UTIs in this region. 


\section{Distribution of phylogenetic groups, adhesin genes, biofilm}

\section{2 formation, and antimicrobial resistance of uropathogenic}

\section{Escherichia coli isolated from hospitalized patients in}

\section{Thailand}

5

6 Nipaporn Tewawong ${ }^{1}$, Siriporn Kowaboot ${ }^{1}$, Yaowaluk Pimainog ${ }^{1}$, Naiyana Watanagul ${ }^{2}$,

7 Thanunrat Thongmee ${ }^{3}$, Yong Poovorawan ${ }^{3}$

8

9

10

$11{ }^{1}$ Faculty of Medical Technology, Rangsit University, Pathum Thani, Thailand

${ }^{2}$ Department of Microbiology, Nopparat Rajathanee Hospital, Khannayao, Bangkok, Thailand

${ }^{3}$ Center of Excellence in Clinical Virology, Department of Pediatrics, Faculty of Medicine,

Chulalongkorn University, Pathumwan, Bangkok, Thailand

15

Corresponding author:

Nipaporn Tewawong ${ }^{1}$

Faculty of Medical Technology, Rangsit University, Pathum Thani, 12000, Thailand

Email: nipaporn.t@rsu.ac.th 


\section{Abstract}

23 Background: Urinary tract infections (UTIs) are the most common bacterial infections and are

24 often caused by uropathogenic Escherichia coli (UPEC). We investigated the distribution of phylogenetic groups, adhesin genes, antimicrobial resistance, and biofilm formation in E. coli isolated from patients with UTIs.

Methods: In the present study, 208 UPEC isolated from Thai patients were classified into phylogenetic groups and adhesin genes were detected using multiplex PCR. Antimicrobial susceptibility testing was performed using agar disk diffusion. The Congo red agar method was used to determine the ability of the UPEC to form biofilm.

Results: The most prevalent UPEC strains in this study belonged to phylogenetic group B2 (58.7\%), followed by group C (12.5\%), group E (12.0\%), and the other groups (16.8\%). Among adhesin genes, the prevalence of fimH (91.8\%) was highest, followed by pap (79.3\%), sfa $(12.0 \%)$, and $a f a(7.7 \%)$. The rates of resistance to fluoroquinolones, trimethoprimsulfamethoxazole, and amoxicillin-clavulanate were $\sim 65 \%, 54.3 \%$, and $36.5 \%$, respectively. The presence of adhesin genes and antibiotic resistance were more frequent in groups B2 and C compared to the other groups. Of the 129 multidrug-resistant UPEC strains, 54\% were biofilm producers. Our findings further indicated that biofilm production was significantly correlated with the pap adhesin gene $(p \leq 0.05)$.

Conclusion: These findings provide molecular epidemiologic data, antibiotic resistance profiles, and the potential for biofilm formation among UPEC strains that can inform further development of the appropriate prevention and control strategies for UTIs in this region. 
45

46

47

48

49

50

51

52

53

54

\section{Introduction}

Urinary tract infections (UTIs) are a common bacterial infection, with 150 million UTI cases observed annually worldwide (Stamm \& Norrby, 2001). Uropathogenic Escherichia coli (UPEC) is the most common causative agent of both uncomplicated and complicated UTIs, accounting for $75 \%$ and $65 \%$ of cases, respectively (Flores-Mireles et al., 2015). Clermont and colleagues developed a new polymerase chain reaction (PCR)-based method to classify the eight phylogenetic groups of E. coli, of which seven are clustered in E. coli sensu stricto (A, B1, B2, C, D, E, and F) and one belongs to Escherichia Clade 1 (Clermont et al., 2013). Several studies have reported that phylogenetic groups B2 and D are associated with extraintestinal infection, while the other groups are more prevalent among diarrheagenic and commensal bacteria (Picard et al., 1999; Kumar, Nahid, \& Zahra, 2017; Ahumada-Santos et al., 2020).

Adherence and colonization are the crucial steps in UTI pathogenesis. UPEC generally use various adhesins to recognize uroepithelium cells and mediate colonization (Flores-Mireles et al., 2015). Type 1 fimbriae consist of a major protein, FimA, that is associated with the ancillary proteins FimF, FimG, and the adhesin FimH, all of which are encoded by the fim gene cluster (Orndorff \& Falkow, 1984). The P fimbriae are encoded by the pap gene cluster, which contains 11 genes ( $p a p A$ to $p a p K$ ) (Fernández \& Berenguer, 2000). P fimbriae promote early colonization of the epithelial cells lining the tubules, while type 1 fimbriae appear to play a role in inter-bacterial binding and biofilm formation (Melican et al., 2011). The S fimbriae are expressed by the $s f a$ operon, which was reported to be most often found in E. coli strains implicated in human meningitis and septicemia (Antao, Wieler, \& Ewers, 2009). The Pindependent, X-binding fimbrial adhesin encoded by the afal operon mediates specific binding to uroepithelial cells and human erythrocyte receptors (Labigne-Roussel \& Falkow, 1988). 
68 Different studies have investigated the presence of the adhesion-encoding genes pap (P

69 fimbriae), $s f a$ (S fimbriae), afa (afimbrial adhesin), and fimH (type 1 fimbriae) across UPEC

70 strains using multiplex PCR (Rahdar et al., 2015; Dadi et al., 2020; Tarchouna et al., 2013;

71 Shetty et al., 2014).

Currently, the empirical treatment of UTIs is an issue of concern due to the increasing rates of antibiotic resistance. The resistance to trimethoprim-sulfamethoxazole (TMP-SMZ), ciprofloxacin, and amoxicillin-clavulanate (AMC) among UPEC isolates is higher in developing countries (ranging from $\sim 50 \%$ to $85 \%$ ) than in developed countries (ranging from $3 \%$ to $40 \%$ ) (Kot, 2019). Routine standard antimicrobial susceptibility testing must be performed in order to reduce the rates of inappropriate empirical antibiotic therapy of UTIs and thereby decrease the occurrence of multidrug-resistant (MDR) UPEC (Adamus-Białek et al., 2018).

Biofilms are microbial communities that adhere to various surfaces, and the cells within a biofilm are encased in self-produced extracellular polymeric matrix (Hall \& Mah, 2017). The ability of UPEC to form biofilms is important, as biofilms increase antimicrobial agent tolerance and facilitate evasion of the urinary tract host defense, contributing to the evolution of MDR strains and the recurrence of UTIs (Mittal, Sharma, \& Chaudhary, 2015).

A study of virulence genes and antimicrobial susceptibility patterns of UPEC in southern Thailand was previously reported (Themphachanal et al., 2015), but there is no information on the new classification of phylogenetic groups or the biofilm-forming ability of UPEC. Therefore, the aim of the present study was to determine the phylogenetic groups, adhesin gene distribution, antimicrobial resistance profiles, and biofilm formation ability of UPEC isolated from patients with UTIs in central Thailand. We also investigated the possible correlation between adhesin genes and the ability to form biofilm. 
91 Materials and Methods

92 Ethical approval

93 E. coli strains were isolated from patients with UTI then identified and collected at the Nopparat

94 Rajathanee Hospital as part of the routine microbiological laboratory. The study protocol was

95 approved by the Ethics Review Board (ERB) of the Research Institute of Rangsit University

96 (DPE.No.RSUERB2018-002). All the bacterial strains were acquired with permission from the

97 Director of Nopparat Rajathanee Hospital.

98

\section{Bacterial strains}

The 208 non-repetitive $E$. coli strains isolated from urine specimens of UTI patients between

February and May 2018 were used from the current study. E. coli strains were isolated from pure cultures and identified in the department of microbiological laboratory in the Nopparat

Rajathanee Hospital. The bacteria were confirmed as E. coli by considering Gram's staining morphology, colony characteristic on MacConkey agar (Oxoid, UK), and biochemical properties (Bergey et al., 1994). The oxidase test, catalase test, sugar fermentation, motility test, indole production, methyl red test, Voges-proskauer reaction, urease production, citrate utilization, and ornithine and lysine decarboxylase test were used as the standard biochemical testing in our laboratory. The only one isolate from each patient was investigated.

\section{Characterization of phylogenetic groups and adhesin genes}

111 Bacterial DNA was extracted using the optimized boiling method (Dashti et al., 2009). The phylogenetic groups of E. coli were characterized using multiplex PCR according to the protocol

113 previously published (Clermont et al., 2013). Table S1 shows the primer sequences and the size 
114 of amplicons. In addition, four adhesin genes, pap, sfa, afa, and fimH, were detected in all

115 isolates using multiplex PCR (Yamamoto et al., 1995; Le Bouguenec, Archambaud, \& Labigne,

116 1992; Struve \& Krogfelt, 1999). The details of the primers and sizes of PCR products are listed

117 in Table S2. The PCR reaction volume contained $15 \mu$ of $2 \mathrm{X}$ AmpMaster ${ }^{\mathrm{TM}} \mathrm{HS}-\mathrm{Taq}$ (GeneAll®,

118 Korea), $10 \mathrm{pmol} / \mu \mathrm{l}$ of each primer, $3 \mu \mathrm{l}$ of DNA template, and DNase-free $\mathrm{H}_{2} \mathrm{O}$ to a final volume

119 of $30 \mu \mathrm{l}$. Amplification was carried out in the Mastercycler ${ }^{\circledR}$ nexus (Eppendorf, Germany) under

120 the following conditions: initial denaturation at $95^{\circ} \mathrm{C}$ for $3 \mathrm{~min}, 45$ cycles of $45 \mathrm{~s}$ denaturation at

$12195^{\circ} \mathrm{C}, 45 \mathrm{~s}$ of primer annealing at $55^{\circ} \mathrm{C}$ (to characterize the phylogenetic groups) and $54^{\circ} \mathrm{C}$ (to

122 amplify the adhesin genes), $60 \mathrm{~s}$ of extension at $72^{\circ} \mathrm{C}$, and further extension for 5 min at $72^{\circ} \mathrm{C}$.

123 PCR products were separated on a $2 \%$ agarose gel with a 100-bp DNA ladder (Fermentas, US)

124 and visualized on a UV trans-illuminator.

126 Antimicrobial susceptibility testing

127 Antimicrobial susceptibility tests were performed using the agar disk diffusion method according 128 to Clinical and Laboratory Standards Institute guidelines (CLSI, 2018). The antibiotic disks

129 (Oxoid, UK) ampicillin $(10 \mu \mathrm{g})$, amoxicillin-clavulanate $(20 / 10 \mu \mathrm{g})$, piperacillin-tazobactam

$130(100 / 10 \mu \mathrm{g})$, cefoperazone-sulbactam $(75 / 30 \mu \mathrm{g})$, cefazolin $(30 \mu \mathrm{g})$, cefotaxime $(30 \mu \mathrm{g})$,

131 ceftriaxone $(30 \mu \mathrm{g})$, ceftazidime $(30 \mu \mathrm{g})$, imipenem $(10 \mu \mathrm{g})$, meropenem $(10 \mu \mathrm{g})$, ertapenem $(10$

$132 \mu \mathrm{g})$, gentamicin $(10 \mu \mathrm{g})$, amikacin $(30 \mu \mathrm{g})$, netilmicin $(30 \mu \mathrm{g})$, ciprofloxacin $(5 \mu \mathrm{g})$, levofloxacin

$133(5 \mu \mathrm{g})$, norfloxacin $(10 \mu \mathrm{g})$, trimethoprim-sulfamethoxazole $(1.25 / 23.75 \mu \mathrm{g})$, and fosfomycin

$134(200 \mu \mathrm{g})$ were used. Escherichia coli ATCC 25922 was used as a control in all antibiogram tests.

135 Whether a strain was MDR was determined on the basis of acquired non-susceptibility to at least

136 one agent in three or more antimicrobial categories (Magiorakos et al., 2012). 


\section{Detection of biofilm formation}

138 The biofilm production of all E. coli strains was determined using the Congo red agar (CRA)

139 method, as previously published (Neupane et al., 2016; Sm et al., 2016; Tajbakhsh et al., 2016).

140 The medium contains brain heart infusion agar $(52 \mathrm{gm} / \mathrm{L})$; sucrose $(36 \mathrm{gm} / \mathrm{L})$ and Congo red dye

$141(0.8 \mathrm{gm} / \mathrm{L})$. The tested organism were cultured on CRA and incubated under the aerobic

142 condition at $37^{\circ} \mathrm{C}$ for 24 to 48 hours. The six color tones of colonies were categorized as follows:

143 very black, black, almost black, which were interpreted as strong, moderate, and weak biofilm

144 producers, respectively, and bordeaux, red, and very red, reported as non-biofilm producers.

\section{Statistical analysis}

147 Chi-square test was used for comparisons of proportions the demographic characteristics of 148 patients. The correlation between phylogenetic group, the presence of adhesin genes, biofilm 149 production, and antimicrobial resistance were determined by performing Pearson's chi-square 150 tests. SPSS version 21 software were used for data analysis (IBM SPSS Inc., Armonk, NY, 151 USA). Results were considered statistically significant if the $p$-value was $\leq 0.05$.

\section{Results}

Among 1,926 patients with symptoms of UTI, a total of 208 isolates were identified as $E$. coli. The demographic characteristics of patients infected with UPEC are shown in Table 1. Among the patients, 154 (74\%) were female and 54 (26\%) were male. Patients were stratified into five different age groups, and those over 65 years represented $63.9 \%$ of all patients. The highest number of UPEC samples was isolated from catheter urine samples $(150,72.1 \%)$. The highest proportion of UPEC isolates came from the internal medicine ward (80, 38.5\%), 
160 followed by the emergency room $(45,21.6 \%)$, intensive care unit $(34,16.3 \%)$, and outpatients $161 \quad(22,10.6 \%)$.

162

163

164

165

166

167

168

169

170

171

172

173

174

175

176

177

178

179

180

181

182

We characterized the phylogenetic groups of E. coli from urine specimens by detecting the $\operatorname{arp} A$ (400 bp), chuA (288 bp), yjaA (211 bp), and TspE4.C2 (152 bp) genes using multiplex PCR (Fig. 1A). Primers specific for the $\operatorname{trp} A(489 \mathrm{bp})$ gene were added to all PCR reactions to provide an internal control. Groups $\mathrm{C}$ and $\mathrm{E}$ were classified by amplification of the $\operatorname{trp} A(219 \mathrm{bp})$ and $\operatorname{arp} A(301 \mathrm{bp})$ genes using specific primers. The majority of the $208 \mathrm{E}$. coli isolates were group B2 (122, 58.7\%), followed by group C (26, 12.5\%), group E (25, 12\%), group A (10, $4.8 \%)$, group F $(9,4.3 \%)$, group D $(6,2.9 \%)$, group B1 $(5,2.4 \%)$, unassignable $(3,1.4 \%)$, and clade I or clade II (2, 1.0\%; Fig. 1B).

Adhesin-encoding genes were successfully amplified by multiplex PCR. The most frequent UPEC adhesin gene was fimH (191, 91.8\%), followed by pap (165, 79.3\%), sfa (25, $12.0 \%)$, and $a f a(16,7.7 \%)$. We also investigated the adhesin gene patterns of the strains (Table 2). Among the isolates, 30 (14.4\%), $167(80.3 \%)$, and $11(5.3 \%)$ possessed 1, 2, and 3 adhesin genes, respectively. A high prevalence of combined fim $H$ and pap genes was significantly found $(69.2 \%, p<0.0001)$. Moreover, the fimH gene has significant association with UPEC phylogenetic groups B2 $(p=0.041)$. There was significant association between phylogenetic group E and two adhesin genes namely pap and afa ( $p=0.002$ and $p<0.0001$, respectively). Similarly, there was significant association between phylogenetic group F and adhesin genes fimH and $s f a$ ( $p=0.005$ and $p=0.044$, respectively) (See Table 3).

We performed antimicrobial susceptibility tests on E. coli strains using different categories of antibiotics. There were significant association between E. coli phylogenetic groups and resistance rates of antibiotics $(p<0.05)$ except ampicillin, gentamicin and trimethoprim- 
183 sulfamethoxazole (Table 4). All isolates showed high rates of resistance to ampicillin (84.1\%),

184 ciprofloxacin (65.4\%), norfloxacin (65.4\%), levofloxacin (64.9\%), trimethoprim-

185 sulfamethoxazole $(54.3 \%)$, cefazolin $(44.7 \%)$, cefotaxime $(43.8 \%)$, ceftriaxone $(43.8 \%)$,

186 ceftazidime (43.8\%), amoxicillin-clavulanate (36.5\%), and gentamicin $(33.7 \%)$. The rates of

187 resistance to other antibiotics were between $\sim 1 \%$ and $6 \%$. E. coli phylogenetic group C had the

188 highest rates of resistance to all antibiotics $(p<0.05)$ except ampicillin, gentamicin, amikacin,

189 netilmicin, and fosfomycin (Table S3). Three isolates (1.4\%) in group C were carbapenems-

190 resistant. Interestingly, most of the 129 isolates $(62.0 \%)$ that were MDR and belonged to group

191 B2 (59.7\%; 77 of 129). However, the lower resistance rates to piperacillin-tazobactam and

192 carbapenems were observed in group B2 ( $p=0.005$ and $p=0.0038$, respectively) (Table S3).

193 The lowest rates of resistance to cephalosporin were observed in group A $(p=0.02)$, while group

$194 \mathrm{D}$ was more susceptible to fluoroquinolones than the other groups $(p=0.01)$. The only one

195 isolate of group A was resistant to fosfomycin $(p<0.0001)$.

196 Using the CRA method, the abilities of bacteria to form biofilm were categorized into

197 four groups based on the color tones of colonies. Among the 95 E. coli strains that could form

198 biofilm, 4 (4.2\%) showed strong biofilm-forming ability, 38 (40.0\%) showed moderate ability,

199 and 53 (55.8\%) showed weak ability. The biofilm-producing strains were predominantly

200 clustered in phylogenetic group B2 (Table 5). Biofilm- and non-biofilm-producing UPEC

201 showed different antimicrobial resistance profiles. Among the biofilm producers, the rate of

202 resistance was highest for ampicillin (90\%), followed by fluoroquinolones (82\%), cephalosporins

$203(50 \%)$, and gentamicin (38\%). No biofilm producer was resistant to carbapenems. In contrast, the

204 non-biofilm producers were more resistant to TMP-SMZ (58\%), followed by piperacillin-

205 tazobactam (7\%) and carbapenems (3\%). The frequency distribution is presented in Fig. 2. The 
206 resistance rate to ciprofloxacin, norfloxacin and levofloxacin among biofilm producers were

207 significantly higher than non-biofilm producers $(p<0.0001$; Fig. 2). Of the 129 MDR E. coli

208 isolates, 54\% were biofilm producers.

209 We also investigated the association between the presence or absence of the four adhesin

210 genes and biofilm formation ability. The results demonstrated that biofilm production was

211 significantly correlated with the presence of pap adhesin gene ( $p \leq 0.05$; Table 6$)$. Among the

212 biofilm producer group, we found the prevalence of pap gene was lower in strong biofilm

213 formers than in weak and moderate.

\section{Discussion}

216 The higher proportion of UTIs in female (74\%) than male (26\%) patients in this study were

217 observed. This is most likely to the anatomical structure of the female urethra, which is shorter,

218 wider, and closer to the anus than that of males. E. coli is common in the gastrointestinal tract

219 flora and can be easily moved from the anus to the urinary tract, leading to UTIs (Dadi et al.,

220 2020). Half of the UTI cases in this study (50\%) were observed in female patients over 65 years

221 of age. In postmenopausal women, the low level of estrogen and high intravaginal $\mathrm{pH}$ are

222 associated with increased bacterial adherence to the uroepithelium cell, which causes UTIs

223 (Johansson et al., 1996; Beyer et al., 2001). Our study included a large number of catheter urine

224 specimens, which was correlated with the high percentage of infections in the over-65 age group.

225 The low immunity level in the elderly puts those of advanced age at a high risk of bacterial

226 infection and is responsible for the high prevalence in catheterized cases (Themphachanal et al., 227 2015). 
Phylogenetic groups B2 and D are common strains implicated in UTIs (Ejrnæs et al.,

229

230

231

232

233

234

235

236

237

238

239

240

241

242

243

244

245

246

247

248

249

2011). In contrast to the results of studies from Uruguay and Southern Thailand, where high

prevalences of phylogenetic group D were found (Themphachanal et al., 2015; Robino et al., 2014), we observed that group B2 was the most prevalent UPEC (58.7\%), followed by group C

$(12.5 \%)$. Our results are in accordance with several studies in which the dominant strain was

found to be group B2. These studies were conducted in North America (45\% prevalence of group

B2) (Johnson et al., 2003), Denmark (67\%) (Ejrnæs et al., 2011), Poland (35\%) (Kot et al., 2016), South Korea (79\%) (Lee et al., 2016), and Ethiopia (30\%) (Dadi et al., 2020). Using a novel PCR-based method (Clermont et al., 2013), we could classify UPEC into groups C, E, and F and clade I, resulting in a lower percentage of strains in groups A, B1, and D than in earlier studies. This finding indicates that the triplex method of phylo-grouping misidentifies groups C, E, and F and clade I as belonging to group A, B1, B2, or D (Kumar, Nahid, \& Zahra, 2017). It had been reveal that some strains $(1.4 \%)$ could not be assigned to a phylogenetic group due to simply relying upon PCR of a few small number of genes. As stated by Clermont et al. (2013), the unassignable strains are more likely the result of large-scale recombination events from two different groups or genome plasticity driven by loss and gain of genes. In this study, $1 \%$ of UPEC belonged to cryptic clade I/II. This is a much lower percentage than in a study conducted in Mexico (9\%) (Kumar, Nahid, \& Zahra, 2017). The cryptic clades are primarily associated with environmental E. coli; thus, the observed results may be related to a lack of good hygiene practices. The different distributions of phylogenetic groups may depend on the geographic area, health status of the host, use of antibiotics, and/or variations in research design and sample size of the studies (Derakhshandeh et al., 2013). 

phylogenetic group B2 strains showed the highest frequency of the adhesin genes in our study.

253 We found a coexistence of fimH and pap genes (69.2\%), indicating a high presence of virulence genes among UPEC isolated from UTI patients in Thailand. This outcome was different from that of a study in Iran, in which the combination of pap and afa virulence genes was more common (Rahdar et al., 2015). The ability of UPEC to form biofilm is a crucial virulence property. We found that $45.7 \%$ of UPEC were biofilm producers and that most of these classified into phylogenetic group B2. This finding demonstrates that biofilm formation may be associated with phylogenetic group B2. The association between biofilm-forming ability and some adhesin genes among UPEC was previously reported (Rahdar et al., 2015; Tajbakhsh et al., 2016; Naves correlation between the pap gene and biofilm production. The negative correlation found closely to significance between $s f a$ gene and biofilm formation $(p=0.06)$, as the prevalence of this gene was lower in biofilm producer. In contrast, no significant correlation was seen between the fimH, or afa genes and biofilm production in the strains evaluated in this study. This finding is in agreement with other studies that did not find significant correlations in clinical isolates of pathogenic E. coli (Reisner et al., 2006; Hancock, Ferrie` res, \& Klemm, 2007). The discrepant results imply that these genes are not the only determinants of biofilm production in UPEC strains; rather, environmental and genetic factors may also be involved (Reisner et al., 2006). Adhesin genes such as fim $H$ are under strict control by phase variation in many strains. The

271 presence of adhesin genes certainly does not imply their expression. It would have been far more 
272 informative if the further study had been able to correlate expression of these genes rather than

273 just their presence or absence by PCR.

It is important to perform antimicrobial susceptibility testing to select the appropriate

275 empiric antibiotic therapy for UTIs. Our findings showed that the rate of resistance to ampicillin

$276(84.1 \%)$ was higher than rates of resistance to other antibiotics. In general, fluoroquinolones are

277 recommended for oral antimicrobial therapy in uncomplicated pyelonephritis. TMP-SMZ is

278 commonly used in the treatment of uncomplicated cystitis, while AMC was a first-line therapy

279 for complicated UTIs (Bonkat et al., 2019). However, our results revealed that rates of resistance

280 to fluoroquinolones, TMP-SMZ, and AMC were $65 \%, 54 \%$, and 37\%, respectively. This result is

281 consistent with a previous mini-review reporting increases in resistance rates of those drugs

282 among UPEC isolates in developing countries (Kot, 2019). This likely emerged due to the

283 widespread use of fluoroquinolones for uncomplicated UTIs or the inappropriate use of TMP-

284 SMZ for empiric UTI treatment (Bartoletti et al., 2016). In this study, the strains in phylogenetic

285 group $\mathrm{C}$ showed the highest rates of antibiotic resistance. In recent decades, the increasing rate of

286 MDR in UPEC has become a public health threat. A high prevalence of MDR UPEC of

287 approximately $62 \%$ was observed in the current study, similar to the findings reported in Iran

288 (60.2\%) (Tajbakhsh et al., 2016) and Nepal (63.2\%) (Ganesh et al., 2019). The majority of MDR

289 UPEC belonged to phylogenetic group B2, consistent with the outcomes reported in South Korea

$290(73 \%)$ (Lee et al., 2016).

291 The present study found that biofilm producer strains were more resistant to

292 ciprofloxacin, norfloxacin and levofloxacin than non-biofilm producers. These results were in

293 agreement with previous studies indicating that the sessile bacterial cells are much less

294 susceptible to antimicrobial agents than nonattached (planktonic) cells (Costerton et al., 1999). A 
295 higher rate of resistance to TMP-SMZ was found among the non-biofilm producers than among

296 the biofilm producers. One explanation for this finding is that these strains may carry the $d h f r$ or

297 dhps gene mutation on chromosomal DNA, which are common causes of resistance to this drug

298 (Huovinen et al., 1995).

299 In conclusion, the majority of UPEC among patients with UTIs in this geographical area

300 belonged to phylogenetic group B2. UPEC in this group also showed the highest prevalence of

301 adhesin genes and biofilm formation. The analysis of the antimicrobial resistance of strains

302 tested in this study showed a high level of resistance to cephalosporins, fluoroquinolones, TMP-

303 SMZ, and AMC among strains belonging to groups B2 and C. Therefore, further study of the

304 molecular epidemiology of UPEC and their antibiotic susceptibility patterns will improve our

305 understanding of the organism and lead to a better management of UTIs.

306

\section{Acknowledgments}

308 We would like to acknowledge the staff of the Center of Excellence in Clinical Virology, Faculty of Medicine, Chulalongkorn University, for their excellent technical assistance. We also thank

310 all of the medical technicians in the hospital for helping with bacteria collection and Ms.

311 Naraumon Beakee, Ms. Pacharida Pattum, Ms. Sakonwan Thanoochan, and Ms. Thanyaporn

312 Sidafong for assistance with the laboratory process. 
317

318

319

320

321

322

323

324

325

326

327

328

329

330

331

332

333

334

335

336

337

338

\section{References}

Adamus-Białek W, Baraniak A, Wawszczak M, Głuszek S, Gad B, Wróbel K, Bator P, Majchrzak M, Parniewski P. 2018. The genetic background of antibiotic resistance among clinical uropathogenic Escherichia coli strains. Molecular biology reports 45(5):1055-1065. DOI: 10.1007/s11033-018-4254-0.

Ahumada-Santos YP, Báez-Flores ME, Díaz-Camacho SP, Uribe-Beltrán MJ, Eslava Campos CA, Parra-Unda JR, Delgado-Vargas F. 2020 Association of phylogenetic distribution and presence of integrons with multidrug resistance in Escherichia coli clinical isolates from children with diarrhoea. Journal of infection and public health 13(5):767-772. DOI:

10.1016/j.jiph.2019.11.019.

Antao EM, Wieler LH, Ewers C. 2009. Adhesive threads of extraintestinal pathogenic Escherichia coli. Gut pathogens 1(1):22. DOI: 10.1186/1757-4749-1-22

Bartoletti R, Cai T, Wagenlehner FM, Naber K, Bjerklund Johansen TE. 2016. Treatment of urinary tract infections and antibiotic stewardship. European Urology Supplements 15(4):817. DOI: 10.1016/j.eursup.2016.04.003.

Bergey DH, Holt JG. 1994. Bergey's manual of determinative bacteriology, 9th edn.

Williams \& Wilkins, Baltimore.

Beyer I, Mergam A, Benoit F, Theunissen C, Pepersack T. 2001. Management of urinary tract infections in the elderly. Zeitschrift fur Gerontologie und Geriatrie 34(2):153-157. DOI:

10.1007/s003910170080.

Bonkat G, Bartoletti RR, Bruyère F, Cai T, Geerlings SE, Köves B, Schubert S, Wagenlehner F. 2019. EAU Guidelines on Urological infection [Internet]. Arnhem (The 
339 Netherlands): European Association of Urology. Available at https://uroweb.org/wp-

340 content/uploads/EAU-Guidelines-on-Urological-infections-2019.pdf. [accessed 2020 June 20].

342 coli phylo-typing method revisited: improvement of specificity and detection of new phylo-

343 groups. Environmental microbiology reports 5(1):58-65. DOI: 10.1111/1758-2229.12019 Laboratory Standards Institute. persistent infections. Science 284(5418):1318-1322. virulence genes and phylogenetics of uropathogenic Escherichia coli among urinary tract infection patients in Addis Ababa, Ethiopia. BMC infectious diseases 20(1):108. DOI: 10.1186/s12879-020-4844-z. a simple method of DNA extraction for molecular techniques. The Journal of the Kuwait Medical Association 41(2):117-122. 
361 infections: phylogenetic groups, virulence factors and biofilm formation. Virulence 2(6):528-

362 537. DOI: 10.4161/viru.2.6.18189.

363

364

365

366

367

368

369

370

371

372

373

374

375

376

377

378

379

380

381

382

Fernández LA, Berenguer J. 2000. Secretion and assembly of regular surface structures in Gram-negative bacteria. FEMS Microbiology Reviews 24(1):21-44. DOI:

10.1111/j.15746976.2000.tb00531.x

Flores-Mireles AL, Walker JN, Caparon M, Hultgren SJ. 2015. Urinary tract infections: epidemiology, mechanisms of infection and treatment options. Nature reviews. Microbiology 13(5):269-284. DOI: 10.1038/nrmicro3432

Ganesh R, Shrestha D, Bhattachan B, Rai G. 2019. Epidemiology of urinary tract infection and antimicrobial resistance in a pediatric hospital in Nepal. BMC infectious diseases 19(1):420. DOI: 10.1186/s12879-019-3997-0.

Hall CW, Mah TF. 2017. Molecular mechanisms of biofilm-based antibiotic resistance and tolerance in pathogenic bacteria. FEMS microbiology reviews 41(3):276-301. DOI:

10.1093/femsre/fux010.

Hancock V, Ferrie` res L, Klemm P. 2007. Biofilm formation by asymptomatic and virulent urinary tract infectious Escherichia coli strains. FEMS microbiology letters 267(1):3037. DOI: 10.1111/j.1574-6968.2006.00507.x.

Huovinen P, Sundström L, Swedberg G, Sköld O. 1995. Trimethoprim and sulfonamide resistance. Antimicrobial agents and chemotherapy 39(2):279-289. DOI:10.1128/aac.39.2.279

Johansson C, Molander U, Milsom I, Ekelund P. 1996. Association between urinary incontinence and urinary tract infections, and fractures in postmenopausal women. Maturitas 23(3):265-271. DOI: 10.1016/0378-5122(95)00982-5. 
origin and virulence genotype in relation to resistance to fluoroquinolones and/or extendedspectrum cephalosporins and cephamycins among Escherichia coli isolates from animals and humans. The Journal of infectious diseases 188(5):759-768.

factors, biofilm-forming ability, and antimicrobial resistance of urinary Escherichia coli strains isolated from hospitalized patients. Turkish journal of medical sciences 46(6):1908-1914.

journal of microbiology 68(4):403-415. DOI: 10.33073/pjm-2019-048 and antimicrobial resistance markers in Escherichia coli from Badin city, Pakistan. Journal of chemotherapy 29(1):8-13. DOI: 10.1080/1120009X.2016.1154682 afimbrial-adhesin-encoding operon (afa) among uropathogenic Escherichia coli isolates. Infection and immunity 56(3):640-648 pap, afa, and $s f a$ adhesin-encoding operons in uropathogenic Escherichia coli strains by polymerase chain reaction. Journal of clinical microbiology 30(5):1189-1193. properties of uropathogenic Escherichia coli strains isolated from patients with urinary tract 
404 infections in South Korea. Letters in applied microbiology 62(1):84-90. DOI:

405 10.1111/lam.12517.

406

Magiorakos AP, Srinivasan A, Carey RB, Carmeli Y, Falagas ME, Giske CG, Harbarth

407

S, Hindler JF, Kahlmeter G, Olsson-Liljequist B, Paterson DL, Rice LB, Stelling J, Struelens MJ, 408 Vatopoulos A, Weber JT, Monnet DL. 2012. Multidrug-resistant, extensively drug-resistant and pandrug-resistant bacteria: an international expert proposal for interim standard definitions for acquired resistance. Clinical microbiology and infection 18(3): 268-281. DOI: 10.1111/j.14690691.2011.03570.x. Dahlfors A. 2011. Uropathogenic Escherichia coli P and Type 1 fimbriae act in synergy in a living host to facilitate renal colonization leading to nephron obstruction. PLoS pathogens 7(2): e1001298. DOI: 10.1371/journal.ppat.1001298 uropathogenic Escherichia coli. Pathogens and global health 109(1):26-29. DOI:

J, Dahbi G, Blanco M, Ponte Mdel C, Soriano F. 2008 Correlation between virulence factors and in vitro biofilm formation by Escherichia coli strains. Microbial pathogenesis 45(2):86-91. DOI: 10.1016/j.micpath.2008.03.003.

424 extended spectrum beta lactamase production in uropathogenic Escherichia coli isolated from 425 the patients suspected of urinary tract infections visiting Shree Birendra Hospital, Chhauni, 
426 Kathmandu, Nepal. Antimicrobial Resistance and Infection Control 15(5):5. DOI:

$427 \quad 10.1186 / \mathrm{s} 13756-016-0104-9$.

Orndorff PE, Falkow S. 1984. Organization and expression of genes responsible for type

1 piliation in Escherichia coli. Journal of bacteriology 159(2):736-744.

430

Picard B, Garcia JS, Gouriou S, Duriez P, Brahimi N, Bingen E, Elion J, Denamur E.

1999. The link between phylogeny and virulence in Escherichia coli extraintestinal infection.

Infection and immunity 67(2):546-553. DOI: 10.1128/iai.67.2.546-553.1999

Rahdar M, Rashki A, Miri HR, Rashki Ghalehnoo M. 2015. Detection of pap, sfa, afa, 434 foc, and fim Adhesin-Encoding Operons in Uropathogenic Escherichia coli Isolates Collected

DOI: $10.5812 / \mathrm{jjm} .22647$.

formation of commensal and pathogenic Escherichia coli strains: impact of environmental and

genetic factors. Journal of bacteriology 188(10):3572-3581. DOI:10.1128/JB.188.10.3572-

3581.2006

Robino L, García-Fulgueiras V, Araujo L, Algorta G, Pírez MC, Vignoli R. 2014.

Urinary tract infection in Uruguayan children: Aetiology, antimicrobial resistance and uropathogenic Escherichia coli virulotyping. Journal of global antimicrobial resistance 2(4):293-298. DOI: 10.1016/j.jgar.2014.08.003.

446 Prevalence of adhesive genes among uropathogenic Escherichia coli strains isolated from 
447 patients with urinary tract infection in Mangalore. Indian journal of medical microbiology

448 32(2):175-178. DOI: 10.4103/0255-0857.129812.

Sm N, Jayakumar K, Aravazhi AN. 2016. The effectiveness of antibiotics against a major

450 uropathogen- Escherichia coli and its biofilm assay by phenotypic methods. International

451 Journal of Research in Medical Sciences 4: 4820-4828.

Stamm WE, Norrby SR. 2001. Urinary tract infections: disease panorama and challenges.

The Journal of infectious diseases 183 Suppl 1, S1-S4. DOI: 10.1086/318850

Struve C, Krogfelt KA. 1999. In vivo detection of Escherichia coli type 1 fimbrial expression and phase variation during experimental urinary tract infection. Microbiology $145(\mathrm{Pt}$ 10):2683-2690. DOI: 10.1099/00221287-145-10-2683.

Tajbakhsh E, Ahmadi P, Abedpour-Dehkordi E, Arbab-Soleimani N, Khamesipour F. 2016. Biofilm formation, antimicrobial susceptibility, serogroups and virulence genes of uropathogenic E. coli isolated from clinical samples in Iran. Antimicrobial resistance and infection control 5:11. DOI: 10.1186/s13756-016-0109-4.

uropathogenic virulence genes in Escherichia coli isolated from patients with urinary tract infection. International journal of infectious diseases 17(6):e450e453. DOI: 10.1016/j.ijid.2013.01.025. profiles of uropathogenic Escherichia coli from patients in a tertiary hospital, southern Thailand. 
469 Yamamoto S, Terai A, Yuri K, Kurazono H, Takeda Y, Yoshida O. 1995. Detection of

470 urovirulence factors in Escherichia coli by multiplex polymerase chain reaction. FEMS

471 immunology and medical microbiology 12(2):85-90. DOI: 10.1111/j.1574-

472 695X.1995.tb00179.x. 


\section{Table $\mathbf{1}$ (on next page)}

Demographic characteristics of patients infected with uropathogenic $E$. coli $(N=208)$ 
1 Table 1 Demographic characteristics of patients infected with uropathogenic E. coli $(\mathrm{N}=208)$

2

\begin{tabular}{|c|c|c|c|c|c|}
\hline \multicolumn{2}{|l|}{ Parameter } & $\begin{array}{l}\text { No. of } \\
\text { isolates (\%) }\end{array}$ & Chi-square & $\begin{array}{l}\text { Degree of } \\
\text { freedom }\end{array}$ & $p$-value \\
\hline \multicolumn{6}{|l|}{ Gender } \\
\hline & Female & 154 (74.0) & $48.08^{a}$ & 1 & $<0.0001$ \\
\hline & Male & $54(26.0)$ & & & \\
\hline
\end{tabular}

\section{Age (years)}

\begin{tabular}{|c|c|c|c|}
\hline$<14$ & $11(5.3)$ & $265.02^{b}$ & 4 \\
\hline $15-24$ & $6(2.9)$ & & \\
\hline $25-44$ & $15(7.2)$ & & \\
\hline $45-64$ & $43(20.7)$ & & \\
\hline$\geq 65$ & $133(63.9)$ & & \\
\hline
\end{tabular}

\section{Type of samples}

$\begin{array}{lllll}\text { Midstream urine } & 58(27.9) & 40.69^{\mathrm{a}} & 1 & <0.0001 \\ \text { catheter urine } & 150(72.1) & & & \end{array}$

\section{Hospital Unit}

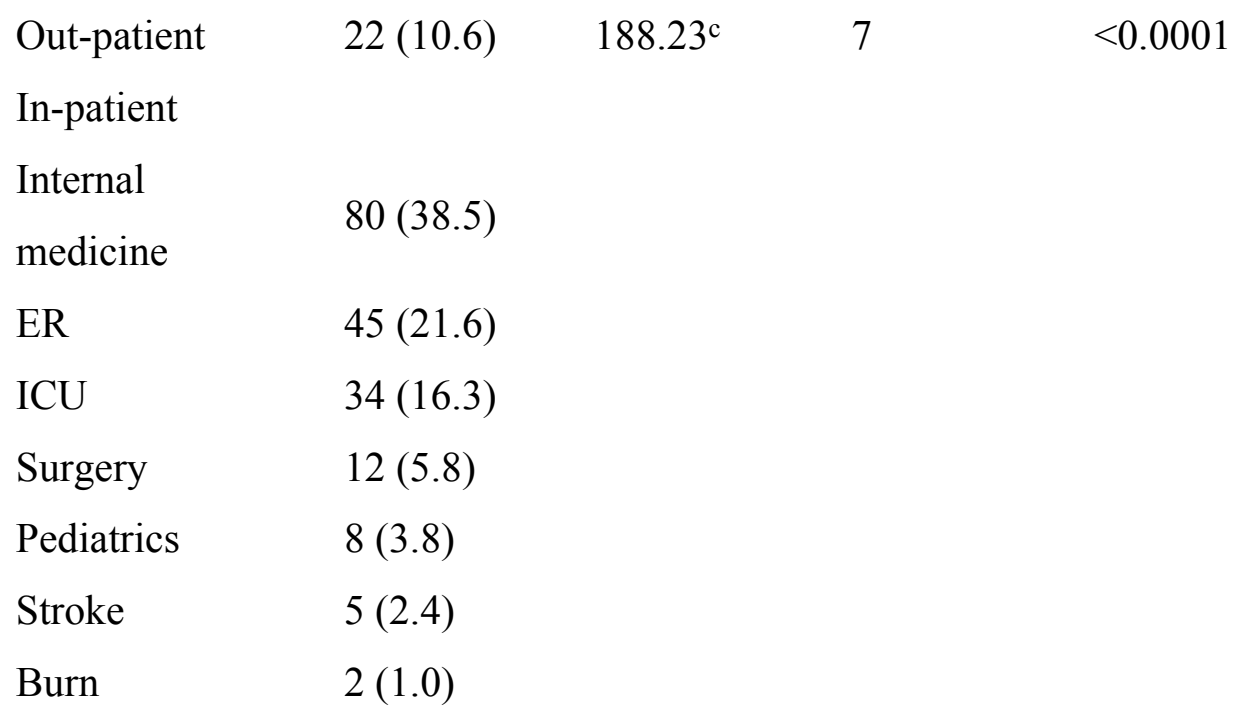

\section{MDR stains}

$\begin{array}{lllll}\text { MDR } & 129(62.0) & 12.02^{\mathrm{a}} & 1 & 0.001 \\ \text { Non-MDR } & 79(38.0) & & & \end{array}$


4 a 0 cells $(.0 \%)$ have expected frequencies less than 5 . The minimum expected cell frequency is $5 \quad 104.0$.

$6 \mathrm{~b} 0$ cells $(.0 \%)$ have expected frequencies less than 5 . The minimum expected cell frequency is $7 \quad 41.6$.

$8{ }^{\mathrm{c}} 0$ cells $(.0 \%)$ have expected frequencies less than 5 . The minimum expected cell frequency is 926.0 .

10

11

12 
Table 2 (on next page)

Profiles of adhesin genes in uropathogenic Escherichia coli strains. 
1 Table 2 Profiles of adhesin genes in uropathogenic Escherichia coli strains.

\begin{tabular}{|c|c|c|c|c|c|}
\hline No. of genes & $\begin{array}{l}\text { Adhesin genes } \\
\text { patterns }\end{array}$ & $\begin{array}{l}\text { No. of isolates } \\
(\%)\end{array}$ & Chi-square & $\begin{array}{l}\text { Degree of } \\
\text { freedom }\end{array}$ & $P$-value \\
\hline \multicolumn{6}{|c|}{1 gene, $n=30(14.4 \%)$} \\
\hline & $\mathrm{fimH}$ & $19(9.1)$ & & & \\
\hline & pap & $4(1.9)$ & & & \\
\hline & $s f a$ & $5(2.4)$ & & & \\
\hline & $a f a$ & $2(1.0)$ & & & \\
\hline \multicolumn{6}{|c|}{2 genes, $n=167(80.3 \%)$} \\
\hline & fimH, pap & $144(69.2)$ & $922.88^{\mathrm{a}}$ & 10 & $<0.0001$ \\
\hline & $f i m H, s f a$ & $11(5.3)$ & & & \\
\hline & $f i m H, a f a$ & $6(2.9)$ & & & \\
\hline & pap, sfa & $2(1.0)$ & & & \\
\hline & pap, afa & $4(1.9)$ & & & \\
\hline \multicolumn{6}{|c|}{3 genes, $n=11(5.3 \%)$} \\
\hline & $f i m H, p a p, s f a$ & $7(3.4)$ & & & \\
\hline & fimH, pap, afa & $4(1.9)$ & & & \\
\hline
\end{tabular}

2

3 a 0 cells $(.0 \%)$ have expected frequencies less than 5 . The minimum expected cell frequency is $4 \quad 18.9$ 


\section{Table 3 (on next page)}

The association between phylogenetic groups and adhesin genes of uropathogenic Escherichia coli isolates. 
1 Table 3 The association between phylogenetic groups and adhesin genes of uropathogenic Escherichia coli isolates.

\begin{tabular}{|c|c|c|c|c|c|c|c|c|c|c|c|c|c|c|c|c|c|c|c|c|c|}
\hline \multirow{3}{*}{\multicolumn{2}{|c|}{ Adhesin genes }} & \multicolumn{20}{|c|}{ Phylogenetic group } \\
\hline & & \multicolumn{4}{|c|}{$\mathrm{B} 2(\mathrm{n}=122)$} & \multicolumn{4}{|c|}{$\mathrm{C}(\mathrm{n}=26)$} & \multicolumn{4}{|c|}{$E(n=25)$} & \multicolumn{4}{|c|}{$\mathrm{A}(\mathrm{n}=10)$} & \multicolumn{4}{|c|}{$F(n=9)$} \\
\hline & & $\mathrm{B} 2$ & $\begin{array}{l}\text { Non- } \\
\mathrm{B} 2\end{array}$ & $\chi^{2}$ & $P$-value & $\mathrm{C}$ & $\begin{array}{l}\text { Non- } \\
\mathrm{C} \\
\end{array}$ & $\chi^{2}$ & $P$-value & E & Non-E & $x^{2}$ & $P$-value & $\mathrm{A}$ & Non-A & $\chi^{2}$ & $P$-value & $\mathrm{F}$ & Non-F & $x^{2}$ & $P$-value \\
\hline \multirow[t]{2}{*}{ fim $H$} & Present & 116 & 75 & 4.166 & 0.041 & 24 & 167 & 0.009 & 0.924 & 22 & 169 & 0.554 & 0.456 & 10 & 181 & 0.935 & 0.334 & 6 & 185 & 7.935 & 0.005 \\
\hline & Absent & 6 & 11 & & & 2 & 15 & & & 3 & 14 & & & 0 & 17 & & & 3 & 14 & & \\
\hline \multirow[t]{2}{*}{ pap } & Present & 100 & 65 & 1.254 & 0.263 & 20 & 145 & 0.105 & 0.746 & 14 & 151 & 9.428 & 0.002 & 10 & 155 & 2.738 & 0.098 & 7 & 158 & 0.014 & 0.907 \\
\hline & Absent & 22 & 21 & & & 6 & 37 & & & 11 & 32 & & & 0 & 43 & & & 2 & 41 & & \\
\hline \multirow[t]{2}{*}{$s f a$} & Present & 19 & 6 & 3.526 & 0.060 & 1 & 24 & 1.877 & 0.171 & 1 & 24 & 1.728 & 0.189 & 0 & 25 & 1.435 & 0.231 & 3 & 22 & 4.041 & 0.044 \\
\hline & Absent & 103 & 80 & & & 25 & 158 & & & 24 & 159 & & & 10 & 173 & & & 6 & 177 & & \\
\hline \multirow[t]{2}{*}{ afa } & Present & 6 & 10 & 3.198 & 0.074 & 0 & 16 & 2.476 & 0.116 & 8 & 8 & 23.645 & 0.000 & 0 & 16 & 0.875 & 0.349 & 1 & 15 & 0.155 & 0.694 \\
\hline & Absent & 116 & 76 & & & 26 & 166 & & & 17 & 175 & & & 10 & 182 & & & 8 & 184 & & \\
\hline
\end{tabular}

\begin{tabular}{|c|c|c|c|c|c|c|c|c|c|c|c|c|c|c|c|c|c|c|c|c|c|}
\hline \multirow{3}{*}{\multicolumn{2}{|c|}{ Adhesin genes }} & \multicolumn{20}{|c|}{ Phylogenetic group } \\
\hline & & \multicolumn{4}{|c|}{$\mathrm{D}(\mathrm{n}=6)$} & \multicolumn{4}{|c|}{$\mathrm{B} 1(\mathrm{n}=5)$} & \multicolumn{4}{|c|}{ Unassignable $(\mathrm{n}=3)$} & \multicolumn{4}{|c|}{ CladeI $(\mathrm{n}=1)$} & \multicolumn{4}{|c|}{ Clade I or II $(\mathrm{n}=1)$} \\
\hline & & $\mathrm{D}$ & $\begin{array}{l}\text { Non- } \\
\mathrm{D}\end{array}$ & $x^{2}$ & $P$-value & $\mathrm{B} 1$ & $\begin{array}{l}\text { Non- } \\
\text { B1 }\end{array}$ & $x^{2}$ & $P$-value & Unassign & $\begin{array}{l}\text { Non- } \\
\text { unassign }\end{array}$ & $x^{2}$ & $P$-value & CladeI & $\begin{array}{l}\text { Non- } \\
\text { cladeI }\end{array}$ & $x^{2}$ & $P$-value & CladeI/II & $\begin{array}{l}\text { Non- } \\
\text { cladeI/II }\end{array}$ & $x^{2}$ & $P$-value \\
\hline \multirow[t]{2}{*}{$\operatorname{fim} H$} & Present & 5 & 186 & 0.594 & 0.441 & 5 & 186 & 0.456 & 0.500 & 2 & 189 & 2.567 & 0.109 & 1 & 190 & 0.089 & 0.765 & $\mathbf{0}$ & 191 & 11.290 & 0.001 \\
\hline & Absent & 1 & 16 & & & 0 & 17 & & & 1 & 16 & & & 0 & 17 & & & 1 & 16 & & \\
\hline \multirow[t]{2}{*}{ pap } & Present & 5 & 160 & 0.060 & 0.806 & 4 & 161 & 0.001 & 0.970 & 3 & 162 & 0.739 & 0.373 & 1 & 164 & 0.262 & 0.609 & 1 & 164 & 0.262 & 0.609 \\
\hline & Absent & 1 & 42 & & & 1 & 42 & & & 0 & 43 & & & 0 & 43 & & & 0 & 43 & & \\
\hline \multirow[t]{2}{*}{$s f a$} & Present & 0 & 25 & 0.844 & 0.358 & 1 & 24 & 0.309 & 0.579 & 0 & 25 & 0.416 & 0.519 & 0 & 25 & 0.137 & 0.711 & 0 & 25 & 0.137 & 0.711 \\
\hline & Absent & 6 & 177 & & & 4 & 179 & & & 3 & 180 & & & 1 & 182 & & & 1 & 182 & & \\
\hline \multirow[t]{2}{*}{$a f a$} & Present & 0 & 16 & 0.515 & 0.473 & 0 & 16 & 0.427 & 0.513 & 1 & 15 & 2.818 & 0.093 & 0 & 16 & 0.084 & 0.772 & 0 & 16 & 0.084 & 0.772 \\
\hline & Absent & 6 & 186 & & & 5 & 187 & & & 2 & 190 & & & 1 & 191 & & & 1 & 191 & & \\
\hline
\end{tabular}

2 


\section{Table 4 (on next page)}

Chi-square test for comparisons of resistance rates to antimicrobial agents among various phylogenetic groups of uropathogenic Escherichia coli isolates. 
1 Table 4 Chi-square test for comparisons of resistance rates to antimicrobial agents among various phylogenetic groups of

2 uropathogenic Escherichia coli isolates.

\begin{tabular}{|c|c|c|c|c|c|c|c|c|c|c|c|c|}
\hline \multirow{3}{*}{$\begin{array}{l}\text { Antimicrobial } \\
\text { resistance rates }\end{array}$} & \multicolumn{10}{|c|}{ Phylogenetic group } & \multirow{3}{*}{ Chi-square } & \multirow{3}{*}{$P$-value } \\
\hline & B2 & $\mathrm{C}$ & $\mathrm{E}$ & A & $\mathrm{F}$ & $\mathrm{D}$ & B1 & Unassignable & CladeI and I or II & Total & & \\
\hline & $\mathrm{n}=122(\%)$ & $\mathrm{n}=26(\%)$ & $\mathrm{n}=25(\%)$ & $\mathrm{n}=10(\%)$ & $\mathrm{n}=9(\%)$ & $\mathrm{n}=6(\%)$ & $\mathrm{n}=5(\%)$ & $\mathrm{n}=3(\%)$ & $\mathrm{n}=2(\%)$ & $\mathrm{n}=208(\%)$ & & \\
\hline \multicolumn{13}{|l|}{ Penicillins } \\
\hline AMP & $101(82.8)$ & $25(96.2)$ & $21(84)$ & $8(80)$ & $6(66.7)$ & $6(100)$ & $4(80)$ & $3(100)$ & $1(50)$ & $175(84.1)$ & 16.707 & 0.054 \\
\hline \multicolumn{13}{|c|}{$\beta$-lactam/ $\beta$-lactamase inhibitor combinations } \\
\hline $\mathrm{AMC}$ & $39(32)$ & $17(65.4)$ & $9(36)$ & $3(30)$ & $4(44.4)$ & $1(16.7)$ & $3(60)$ & 0 & 0 & $76(36.5)$ & 16.906 & 0.050 \\
\hline TZP & $2(1.6)$ & 7 (26.9) & $1(4)$ & 0 & $1(11.1)$ & 0 & 0 & 0 & 0 & $11(5.3)$ & 29.961 & 0.000 \\
\hline SCF & $5(4.1)$ & $7(26.9)$ & $1(4)$ & 0 & 0 & 0 & 0 & 0 & 0 & $13(6.3)$ & 22.477 & 0.007 \\
\hline \multicolumn{13}{|l|}{ Cephalosporins } \\
\hline $\mathrm{KZ}$ & $54(44.3)$ & $18(69.2)$ & $11(44)$ & $1(10)$ & $5(55.6)$ & $2(33.3)$ & $1(20)$ & $1(33.3)$ & 0 & $93(44.7)$ & 15.248 & 0.084 \\
\hline CTX & $53(43.4)$ & $18(69.2)$ & $11(44)$ & $1(10)$ & $5(55.6)$ & $1(16.7)$ & $1(20)$ & $1(33.3)$ & 0 & $91(43.8)$ & 16.977 & 0.049 \\
\hline $\mathrm{CRO}$ & $53(43.4)$ & $18(69.2)$ & $11(44)$ & $1(10)$ & $5(55.6)$ & $1(16.7)$ & $1(20)$ & $1(33.3)$ & 0 & $91(43.8)$ & 16.977 & 0.049 \\
\hline CAZ & $52(42.6)$ & $18(69.2)$ & $11(44)$ & $1(10)$ & $5(55.6)$ & $1(16.7)$ & $2(40)$ & $1(33.3)$ & 0 & $91(43.8)$ & 16.977 & 0.049 \\
\hline \multicolumn{13}{|l|}{ Carbapenems } \\
\hline IPM & 0 & $3(11.5)$ & 0 & 0 & 0 & 0 & 0 & 0 & 0 & $3(1.4)$ & 21.307 & 0.011 \\
\hline MEM & 0 & $3(11.5)$ & 0 & 0 & 0 & 0 & 0 & 0 & 0 & $3(1.4)$ & 21.307 & 0.011 \\
\hline ERT & 0 & $3(11.5)$ & 0 & 0 & 0 & 0 & 0 & 0 & 0 & $3(1.4)$ & 21.307 & 0.011 \\
\hline \multicolumn{13}{|l|}{ Aminoglycosides } \\
\hline $\mathrm{CN}$ & 43 (33.6) & $12(46.2)$ & $9(36)$ & $1(10)$ & $4(44.4)$ & $1(16.7)$ & $1(20)$ & 0 & 0 & $70(33.7)$ & 10.759 & 0.293 \\
\hline $\mathrm{AK}$ & 0 & 0 & 0 & 0 & $1(11.1)$ & 0 & 0 & 0 & 0 & $1(0.5)$ & 25.121 & 0.003 \\
\hline NET & 0 & 0 & 0 & 0 & $1(11.1)$ & 0 & 0 & 0 & 0 & $1(0.5)$ & 25.121 & 0.003 \\
\hline \multicolumn{13}{|c|}{ Fluoroquinolones } \\
\hline CIP & $87(71.3)$ & $25(96.2)$ & $10(40)$ & $4(40)$ & $5(55.6)$ & $1(16.7)$ & $2(40)$ & $2(66.7)$ & 0 & $136(65.4)$ & 36.148 & 0.000 \\
\hline NOR & $88(72.1)$ & $25(96.2)$ & $10(40)$ & $4(40)$ & $5(55.6)$ & $1(16.7)$ & $1(20)$ & $2(66.7)$ & 0 & $136(65.4)$ & 36.148 & 0.000 \\
\hline LEV & $86(70.5)$ & $25(96.2)$ & $10(40)$ & $4(40)$ & $5(55.6)$ & $1(16.7)$ & $2(40)$ & $2(66.7)$ & 0 & 135 (64.9) & 35.411 & 0.000 \\
\hline
\end{tabular}




\begin{tabular}{|c|c|c|c|c|c|c|c|c|c|c|c|c|}
\hline \multicolumn{13}{|c|}{ Folate pathway inhibitors } \\
\hline SXT & $61(50)$ & $20(76.9)$ & $16(64)$ & $5(50)$ & $5(55.6)$ & $4(66.7)$ & 0 & $1(33.3)$ & 0 & $113(54.3)$ & 10.853 & 0.286 \\
\hline \multicolumn{13}{|c|}{ Fosfomycins } \\
\hline
\end{tabular}

3

4 Amp, ampicillin; AMC, amoxicillin-clavulanic acid; TZP, piperacillin-tazobactam; SCF, cefoperazone-sulbactam; KZ, cefazolin;

5 CTX, cefotaxime; CRO, ceftriaxone; CAZ, ceftazidime; CN, gentamicin; CIP, ciprofloxacin; NOR, norfloxacin; LEV, levofloxacin;

6 SXT, trimethoprim-sulfamethoxazole; IPM, Imipenem; MEM, meropenem; ERT, ertapenem; CN, gentamicin; AK, amikacin; NET,

7 netilmicin; FOS, fosfomycin 


\section{Table 5 (on next page)}

Biofilm forming ability among various phylogenetic groups of uropathogenic Escherichia coli isolates. 
1 Table 5 Biofilm forming ability among various phylogenetic groups of uropathogenic

2 Escherichia coli isolates.

\begin{tabular}{|c|c|c|c|c|}
\hline \multirow[t]{2}{*}{ Phylogenetic group } & \multicolumn{4}{|c|}{ Prevalence of biofilm formation ability } \\
\hline & Strong $(n=4), \%$ & Moderate $(n=38), \%$ & Weak $(n=53), \%$ & Absent $(n=113), \%$ \\
\hline $\mathrm{B} 2(\mathrm{n}=122)$ & $3(2.5)$ & $36(29.5)$ & $46(37.7)$ & $37(30.3)$ \\
\hline$C(n=26)$ & 0 & 0 & $3(11.5)$ & $23(88.5)$ \\
\hline$E(n=25)$ & 0 & 0 & $1(4)$ & $24(96)$ \\
\hline$A(n=10)$ & 0 & 0 & 0 & $10(100)$ \\
\hline$F(n=9)$ & 0 & $1(11.1)$ & $1(11.1)$ & $7(77.8)$ \\
\hline $\mathrm{D}(\mathrm{n}=6)$ & 0 & 0 & 0 & $6(100)$ \\
\hline $\mathrm{B} 1(\mathrm{n}=5)$ & $1(20)$ & 0 & $1(20)$ & $3(60)$ \\
\hline Unassignable $(\mathrm{n}=3)$ & 0 & $1(33.3)$ & 0 & $2(66.7)$ \\
\hline CladeI $(\mathrm{n}=1)$ & 0 & 0 & 0 & $1(100)$ \\
\hline Clade I or II $(\mathrm{n}=1)$ & 0 & 0 & $1(100)$ & 0 \\
\hline
\end{tabular}

3 


\section{Table 6 (on next page)}

Prevalence of virulence genes among various groups of different biofilm formation ability. 
1 Table 6 Prevalence of virulence genes among various groups of different biofilm formation ability.

\begin{tabular}{|c|c|c|c|c|c|c|c|}
\hline \multirow{2}{*}{$\begin{array}{l}\text { Virulence } \\
\text { genes }\end{array}$} & \multicolumn{7}{|c|}{ Percentage of biofilm formation ability } \\
\hline & $\begin{array}{l}\text { Strong } \\
(\mathrm{n}=4), \%\end{array}$ & $\begin{array}{l}\text { Moderate } \\
(n=38), \%\end{array}$ & $\begin{array}{l}\text { Weak } \\
(n=53), \%\end{array}$ & $\begin{array}{l}\text { Total } \\
(n=95), \%\end{array}$ & $\begin{array}{l}\text { Absent } \\
(\mathrm{n}=113), \%\end{array}$ & $\begin{array}{l}\text { Pearson } \\
\text { Chi-square }\end{array}$ & $p$-value \\
\hline $\mathrm{fimH}$ & $4(100)$ & $37(97.4)$ & $49(92.5)$ & $90(94.7)$ & $101(89.4)$ & $1.97^{\mathrm{a}}$ & 0.16 \\
\hline pap & $2(50)$ & $35(92.1)$ & $44(83.0)$ & $81(85.3)$ & $84(74.3)$ & $3.76^{\mathrm{b}}$ & 0.05 \\
\hline$s f a$ & 0 & $1(2.6)$ & $6(11.3)$ & $7(7.4)$ & $18(15.9)$ & $3.58^{c}$ & 0.06 \\
\hline$a f a$ & 0 & $2(5.3)$ & $3(5.7)$ & $5(5.3)$ & $11(9.7)$ & $1.45^{\mathrm{d}}$ & 0.23 \\
\hline
\end{tabular}

3

$4 \quad P$-values were calculated using the Pearson Chi-squared test. P-values $\leq 0.05$ are indicated in bold.

5 a 0 cells $(.0 \%)$ have expected count less than 5 . The minimum expected count is 7.76 .

$6 \mathrm{~b}^{\mathrm{b}} 0$ cells $(.0 \%)$ have expected count less than 5. The minimum expected count is 19.64.

7 c 0 cells $(.0 \%)$ have expected count less than 5 . The minimum expected count is 11.42 .

$8 \mathrm{~d} 0$ cells $(.0 \%)$ have expected count less than 5. The minimum expected count is 7.31 . 


\section{Figure 1}

The distribution of phylogenetic groups among uropathogenic Escherichia coli isolates by the new Clermont phylo-typing method.

(A) Multiplex PCR profiles for specific uropathogenic Escherichia coli isolates by detecting the arpA (400 bp), chuA (288 bp), yjaA (211 bp), and TspE4.C2 (152 bp) genes. Lane M, 100-base pair ladder (Fermantas); Lane 1 , group B2 $(-,+,+,+)$; Lane 2 , group B1 $(+,-,-,+)$; Lane 3, group D or E $(+,+,-,-)$; Lane 4, group B2 $(-,+,+,+)$; Lane 5 , group D or E $(+,+,-,-)$; Lane 6 , group B2 $(-,+,+,+)$; Lane 7 , group B2 $(-,+,+,+)$; Lane 8, group B2 $(-,+,+,+)$; Lane 9, group A or C $(+,-,+,-)$; Lane NC, negative control. The trpA (489 bp) internal control gene appeared in all samples except the negative control. Distilled water without any DNA as negative controls was used in PCR experiments. (B) The percentage of phylogenetic groups among uropathogenic Escherichia coli isolates.

A

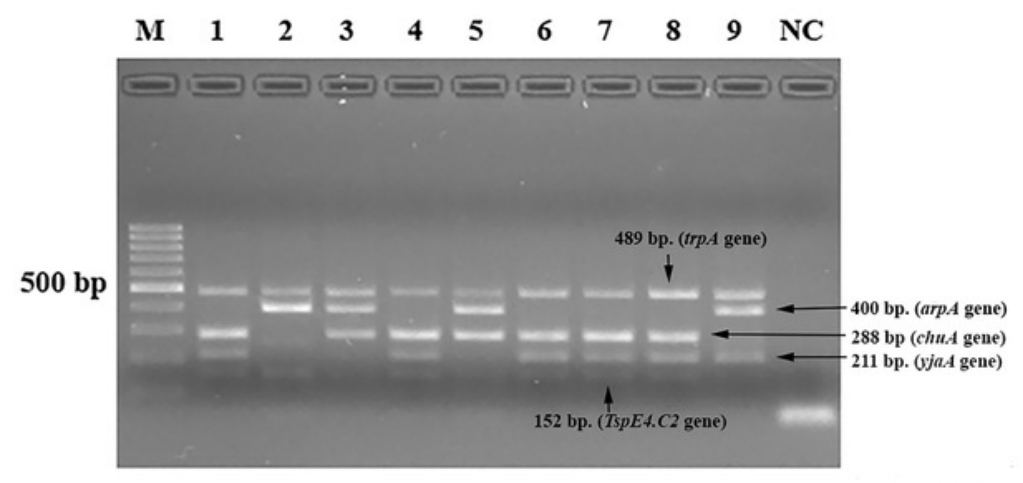

B

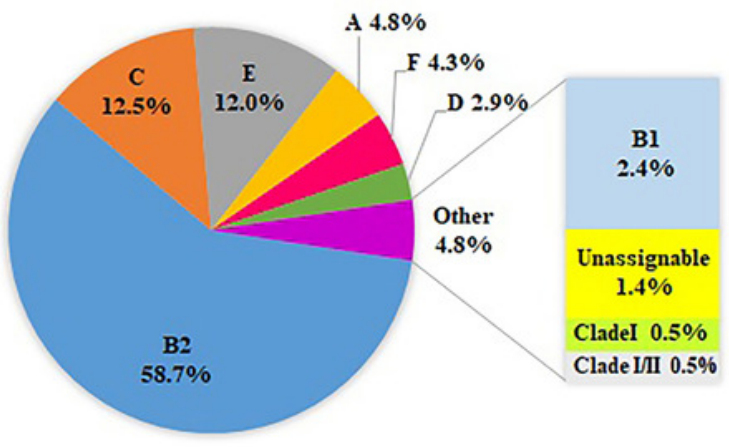




\section{Figure 2}

Comparison of antibiotic resistance between biofilm producers and non-biofilm producers.

Uropathogenic $E$. coli strains were evaluated for in vitro susceptibility to nineteen antibiotics: Amp, ampicillin; AMC, amoxicillin-clavulanic acid; TZP, piperacillin-tazobactam; SCF, cefoperazone-sulbactam; KZ, cefazolin; CTX, cefotaxime; CRO, ceftriaxone; CAZ, ceftazidime; CN, gentamicin; CIP, ciprofloxacin; NOR, norfloxacin; LEV, levofloxacin; SXT, trimethoprimsulfamethoxazole; IPM, Imipenem; MEM, meropenem; ERT, ertapenem; CN, gentamicin; AK, amikacin; NET, netilmicin; FOS, fosfomycin. Bar graphs show the percentage of antibiotic resistance among biofilm producers in blue and non-biofilm producers in orange.

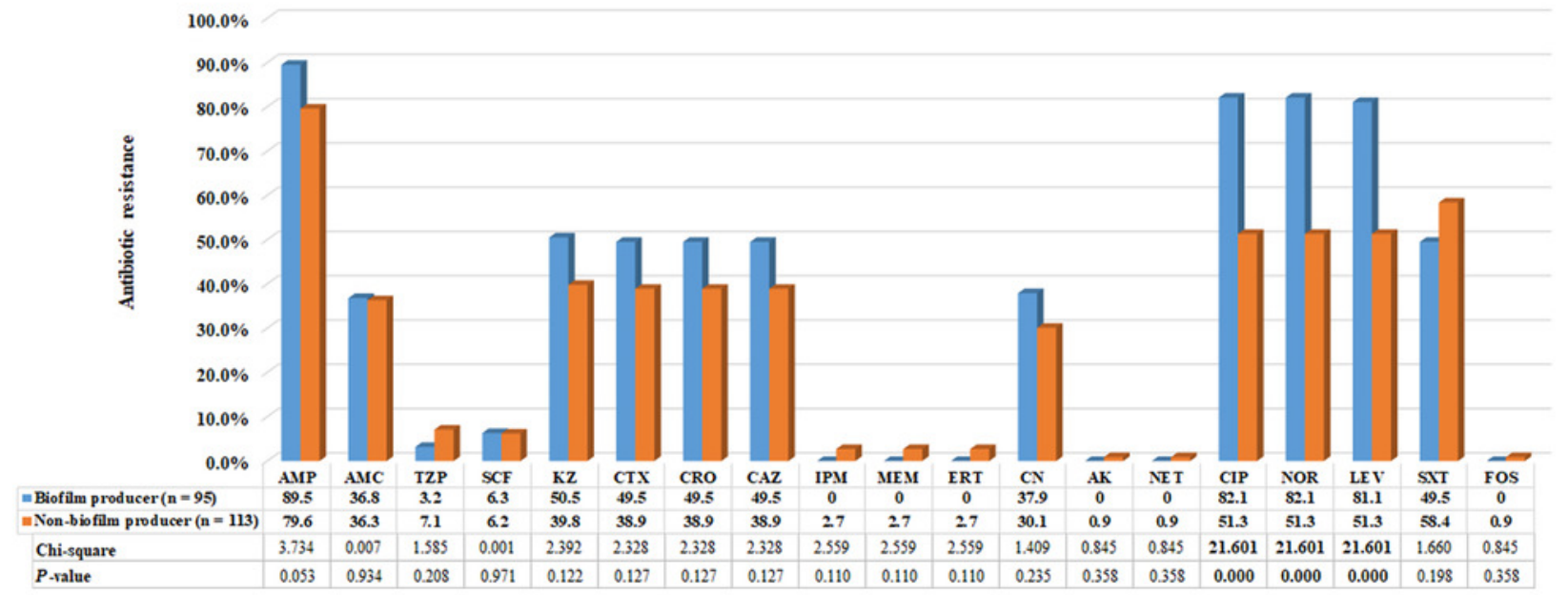

